\title{
Credit Risk Evaluation Based on LINMAP
}

\author{
Tai-yong Mou ${ }^{1}$, Zong-fang Zhou ${ }^{1}$, and Yong $\mathrm{Shi}^{2}$ \\ ${ }^{1}$ Management School, University of Electronic Science \& Technology of China, \\ Chengdu Sichuan 610054 P.R. China \\ moutaiyong@163. com \\ ${ }^{2}$ Chinese Academy of Science Research Center on Data Technology \\ and Knowledge Economy, Beijing 100080 P.R. China \\ yshi@gucas.ac.cn
}

\begin{abstract}
This paper deals with customer's credit risk assessment. We put forward a method based on the Linear Programming Technique for Multidimensional Analysis of Preference (LINMAP). The method is used to develop a credit risk assessment model using a large sample of firms derived from the loan portfolio of a leading Construction Bank of China. The model gave us the method to determine the optimal credit evaluation weights and ideal point. Further we give an example for its application.
\end{abstract}

\section{Introduction}

Credit risk assessment is a significant area of financial management which is of major interest to practitioners, financiers and credit analysts. Considerable attention has been paid in this field from the theoretical and academic points during the last several decades[1-17]. Financial and operational researchers have tried to relate the characteristics of a firm (Financial ratios and strategic variables) to its credit risk[1-5]. According to this relationship the components of credit risk are identified, and decision models are developed to assess credit risk and the corresponding credit worthiness of firms as accurately as possible. The models include Z-score[6,7], discriminant analysis (DA) [8], logit analysis (LA) and probit analysis (PA) and more.

The main purpose of this paper is to investigate the potentials and the applicability of a new discrimination method in credit risk assessment, based on the linear programming technique for multidimensional analysis of preference (LINMAP)[9]. The LINMAP method employs a distance discrimination procedure to determine the class to which the firms under consideration belong.

\section{The Linear Programming Technique Based on Data Mining}

Supposing the commercial bank will provides a loan for $m$ customers, to evaluate the customers' credit, they employ $n$ indexes. So $m$ firms and $n$ indexes form a credit decision space[10-17]. In this credit decision space, every customer's credit corresponds to a point respectively. If the customer's best credit (the bank's preference) can be denoted with an ideal point in the decision space, the customer's credit can be 
described with a weighted distance. In the credit decision space, the weighted distance between every point $\left(x_{i 1}, x_{i 2}, \cdots, x_{i n}\right)$ and ideal point $\left(x_{1}^{*}, x_{2}^{*}, \cdots, x_{n}^{*}\right)$ is

$$
d_{i}=\left[\sum_{j=1}^{n} w_{j}\left(x_{i j}-x_{j}^{*}\right)^{2}\right]^{\frac{1}{2}}, i=1,2, \cdots, m .
$$

Where, $w_{j},(j=1,2, \cdots, n)$ is the $i$-th index's weight. It presents the importance of $i$-th index. At the same time, the square distance can be denoted

$$
S_{i}=d_{i}^{2}=\sum_{j=1}^{n} w_{j}\left(x_{i j}-x_{j}^{*}\right)^{2}, i=1,2, \cdots, m \text {. }
$$

In (2), $w$ and $x^{*}$ are unknown. We can get them by using a training sample.

Using the information in the training sample, we have a sequence relation $\left(F_{k}, F_{l}\right)$. For simplicity, we substitute $(k, l)$ for sequence relation $\left(F_{k}, F_{l}\right)$. The $(k, l)$ means that $k$-th customer's credit is better than $l$-th customer's. Further, we can get a sequence relation $\operatorname{set} Q=\{(k, l)\}$. Obviously, there are $n(n-1) / 2$ elements in set $Q$, if we compare every two customer's credit.

We can calculate the weighted distance between $k$-th customer or $l$-th customer and ideal point, if we can find out $w$ and $x^{*}$. They are

$$
S_{k}=\sum_{j=1}^{n} w_{j}\left(x_{k j}-x_{j}^{*}\right)^{2} \text { and } S_{l}=\sum_{j=1}^{n} w_{j}\left(x_{l j}-x_{j}^{*}\right)^{2} \text {. }
$$

In (3), $x_{k j}$ is the value of the $k$-th customer to the $j$-th index. Similarly the value of the $l$-th customer to the $j$-th index is $x_{l j}$.

In set $Q$, if every sequence relation $(k, l)$ satisfied

$$
S_{l} \geq S_{k}
$$

the $k$-th customer's credit is not worse than the $l$-th customer's. It is consistent with the information in training sample. Otherwise, if

$$
S_{l}<S_{k}
$$

the $k$-th customer's credit is worse than the $l$-th customer's. It is not consistent with information in training sample. Apparently, if the training sample is large enough, the weighted distance should be in accordance with the information of training sample. For measuring the degree of inconsistency between the weighted distances and the training sample information, we have to give a definition. 
Definition 1. let $B=\sum_{(k, l) \in Q}\left(S_{l}-S_{k}\right)^{-}$, where

$$
\left(S_{l}-S_{k}\right)^{-}=\left\{\begin{array}{cll}
0, & \text { if } & S_{l} \geq S_{k}, \\
S_{k}-S_{l}, & \text { if } & S_{l}<S_{k},
\end{array}=\max \left(0 ;\left(S_{k}-S_{l}\right)\right)\right. \text {. }
$$

$B$ is called inconsistent degree between the weighted distances and the training sample information.

From definition 1, we know

$$
\left(S_{l}-S_{k}\right)^{-}=0 \text { if } S_{l} \geq S_{k} \text { and }\left(S_{l}-S_{k}\right)^{-}>0 \text { if } S_{l}<S_{k}
$$

The more different between $S_{l}$ and $S_{k}$, the inconsistent degree is deeper. $\left(S_{l}-S_{k}\right)^{-}=S_{k}-S_{l}$ can measure the inconsistent degree. To finding out optimal $w^{*}$ and $x^{*}$, we have to minimize $B$.

Definition 2. let $G=\sum_{(k, l) \in Q}\left(S_{l}-S_{k}\right)^{+}$, where

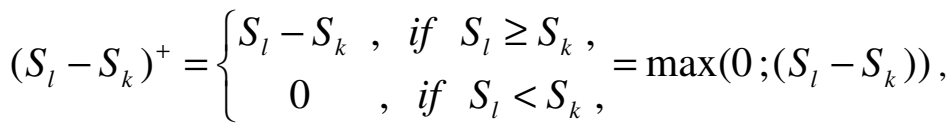

calling $G$ is consistent degree between the weighted distances and the training sample information. From definition 2, we know

$$
\left(S_{l}-S_{k}\right)^{-}=0 \text { if } S_{l}<S_{k} ; \quad\left(S_{l}-S_{k}\right)^{-}>0 \text { if } S_{l} \geq S_{k} .
$$

The more different between $S_{l}$ and $S_{k}$, the consistent degree is deeper. $\left(S_{l}-S_{k}\right)^{-}=S_{l}-S_{k}$ can measure the consistent degree.

We can minimize $B$, which subject to $G>B$ or $G-B=h>0$, where $h$ is a small positive real number. From definition 1 and definition 2, we have

$$
\left(S_{l}-S_{k}\right)^{+}-\left(S_{l}-S_{k}\right)^{-}=S_{l}-S_{k} .
$$

Then

$$
\begin{aligned}
G-B & =\sum_{(k, l) \in Q}\left(S_{l}-S_{k}\right)^{+}-\sum_{(k, l) \in Q}\left(S_{l}-S_{k}\right)^{-} \\
& =\sum_{(k, l) \in Q}\left[\left(S_{l}-S_{k}\right)^{+}-\left(S_{l}-S_{k}\right)^{-}\right] \\
& =\sum_{(k, l) \in Q}\left(S_{l}-S_{k}\right)=h .
\end{aligned}
$$


So, we can get $w$ and $x^{*}$ by solving problem (10).

$$
\begin{gathered}
\min B=\max _{(k, l) \in Q}\left\{0,\left(S_{k}-S_{l}\right)\right\} \\
\text { s.t. } \quad\left(S_{l}-S_{k}\right)=h .
\end{gathered}
$$

Solving problem (10) is equivalent to solving problem (11).

$$
\left\{\begin{array}{cc} 
& \min \sum_{(k, l)} \lambda_{k l} \\
\text { s.t. } & S_{l}-S_{k}+\lambda_{k l} \geq 0, \text { all }(k, l) \in Q \\
& \sum_{(k, l)}\left(S_{l}-S_{k}\right)=h \\
& \lambda_{k l} \geq 0, \quad a \mathrm{ll}(k, l) \in Q .
\end{array}\right.
$$

From (3), we have

$$
\begin{aligned}
S_{l}-S_{k} & =\sum_{j=1}^{n} w_{j}\left(x_{l j}-x_{j}^{*}\right)^{2}-\sum_{j=1}^{n} w_{j}\left(x_{k j}-x_{j}^{*}\right)^{2} \\
& =\sum_{j=1}^{n} w_{j}\left(x_{l j}^{2}-x_{k j}^{2}\right)-2 \sum_{j=1}^{n} w_{j} x_{j}^{*}\left(x_{l j}-x_{k j}\right) .
\end{aligned}
$$

Because $w_{j}$ and $x_{j}^{*}$ are unknown, we institute variable $v_{j}$ for $w_{j} x_{j}^{*}$. So, problem (11) is equivalent to problem (13)

$$
\left\{\begin{array}{c}
\min \sum_{(k, l)} \lambda_{k l} \\
\text { s.t. } \sum_{j=1}^{n} w_{j}\left(x_{l j}^{2}-x_{k j}^{2}\right)-2 \sum_{j=1}^{n} v_{j}\left(x_{l j}-x_{k j}\right)+\lambda_{k l} \geq 0, \\
\operatorname{all}(k, l) \in Q, \\
\sum_{j=1}^{n} w_{j} \sum_{(k, l) \in Q}\left(x_{l j}^{2}-x_{k j}^{2}\right)-2 \sum_{j=1}^{n} v_{j} \sum_{(k, l) \in Q}\left(x_{l j}-x_{k j}\right)=h, \\
\lambda_{k l} \geq 0, \operatorname{all}(k, l) \in Q .
\end{array}\right.
$$

By solving (13), we get all indexes' optimal weight $w^{*}$ and ideal point in credit decision space $x^{*}$. 


$$
w^{*}=\left(\begin{array}{c}
w_{1}^{*} \\
w_{2}^{*} \\
\vdots \\
w_{n}^{*}
\end{array}\right), v^{*}=\left(\begin{array}{c}
v_{1}^{*} \\
v_{2}^{*} \\
\vdots \\
v_{n}^{*}
\end{array}\right) \text { and } x^{*}=\left(\begin{array}{c}
v_{1}^{*} / w_{1}^{*} \\
v_{2}^{*} / w_{2}^{*} \\
\vdots \\
v_{n}^{*} / w_{n}^{*}
\end{array}\right)
$$

Then we can compute the weighted distance $S$ between every customer's credit and ideal point. The value of $S$ is smaller, the customer's credit is better.

\section{An Example for Application}

To illustrate the model of the LINMAP method, consider a simple example consisting of 50 firms $F_{1}, F_{2}, \ldots, F_{50}$, evaluated along five financial ratios $\left(x_{1}\right.$ : retained earnings/total assets, $x_{2}$ : earnings before interest and taxes/total assets, $x_{3}$ : net profit/total assets, $x_{4}$ : net profit after taxes/total assets, $x_{5}$ : liquid assets/total assets). The firms are

Table 1. Data in the training sample

\begin{tabular}{c|cccccc}
\hline Indexes & & & & & \\
\hline
\end{tabular}


Table 2. Square distance of firms in training sample

\begin{tabular}{c|cccccc}
\hline Firms & \multicolumn{5}{|c}{ Square distance } & Categories \\
\hline F1 $\sim$ F5 & 0.0954 & 0.0966 & 0.1011 & 0.1049 & 0.1036 & 1 \\
F6 F10 & 0.1050 & 0.1058 & 0.1055 & 0.1058 & 0.1058 & 2 \\
F11 F15 & 0.1063 & 0.1072 & 0.1081 & 0.1058 & 0.1093 & 3 \\
F16 F20 & 0.1068 & 0.1092 & 0.1086 & 0.1083 & 0.1083 & 4 \\
F21 F F25 & 0.1068 & 0.1083 & 0.1115 & 0.1092 & 0.1097 & 5 \\
\hline
\end{tabular}

Table 3. Data in examination sample

\begin{tabular}{|c|c|c|c|c|c|c|}
\hline Firms & $\mathrm{x}_{1}$ & $\mathrm{x}_{2}$ & $\mathrm{x}_{3}$ & $\mathrm{x}_{4}$ & $\mathrm{x}_{5}$ & Categories \\
\hline F26 & 0.00 & 0.04 & 0.04 & 0.82 & 0.62 & 1 \\
\hline F27 & 0.03 & 0.06 & 0.01 & 0.74 & 0.37 & 1 \\
\hline F28 & 0.05 & 0.00 & 0.01 & 0.57 & 0.62 & 1 \\
\hline F29 & 0.07 & 0.18 & -0.03 & 0.58 & 0.64 & 1 \\
\hline F30 & 0.07 & 0.01 & 0.00 & 0.72 & 0.59 & 1 \\
\hline F31 & 0.04 & 0.00 & 0.00 & 0.40 & 0.44 & 2 \\
\hline F32 & 0.04 & 0.10 & 0.01 & 0.50 & 0.34 & 2 \\
\hline F33 & 0.07 & 0.10 & 0.01 & 0.17 & 0.24 & 2 \\
\hline F34 & 0.07 & 0.12 & 0.04 & 0.45 & 0.45 & 2 \\
\hline F35 & 0.13 & 0.04 & 0.04 & 0.23 & 0.36 & 2 \\
\hline F36 & 0.09 & 0.08 & 0.00 & 0.70 & 0.79 & 3 \\
\hline F37 & 0.15 & 0.09 & 0.00 & 0.65 & 0.80 & 3 \\
\hline F38 & 0.17 & -0.12 & 0.00 & 0.65 & 0.82 & 3 \\
\hline F39 & 0.41 & 0.09 & -0.01 & 0.58 & 0.71 & 3 \\
\hline F40 & 0.46 & -0.04 & -0.01 & 0.79 & 0.99 & 3 \\
\hline F41 & 0.03 & 0.08 & 0.04 & 0.42 & 0.71 & 4 \\
\hline F42 & 0.13 & 0.16 & 0.14 & 0.23 & 0.36 & 4 \\
\hline F43 & 0.14 & 0.11 & 0.04 & 0.38 & 0.53 & 4 \\
\hline F44 & 0.17 & 0.12 & 0.18 & 0.24 & 0.41 & 4 \\
\hline F45 & 0.19 & 0.08 & 0.08 & 0.34 & 0.53 & 4 \\
\hline F46 & 0.23 & 0.11 & 0.01 & 0.27 & 0.50 & 5 \\
\hline F47 & 0.33 & 0.08 & 0.07 & 0.46 & 0.79 & 5 \\
\hline F48 & 0.37 & 0.19 & 0.01 & 0.62 & 0.99 & 5 \\
\hline F49 & 0.45 & 0.00 & 0.06 & 0.43 & 0.89 & 5 \\
\hline F50 & 0.55 & 0.18 & 0.05 & 0.26 & 0.80 & 5 \\
\hline
\end{tabular}

Table 4. Square distance of firms in examination sample

\begin{tabular}{c|cccccc}
\hline Firms & \multicolumn{5}{|c}{ Square distance } & Categories \\
\hline F26 F30 & 0.1038 & 0.0999 & 0.1051 & 0.1023 & 0.1029 & 1 \\
F31 F35 & 0.1045 & 0.1042 & 0.1060 & 0.1047 & 0.1056 & 2 \\
F36 F40 & 0.1070 & 0.1072 & 0.1054 & 0.1068 & 0.1057 & 3 \\
F41 F45 & 0.1069 & 0.1067 & 0.1063 & 0.1065 & 0.1062 & 4 \\
F46 F50 & 0.1097 & 0.1076 & 0.1099 & 0.1083 & 0.1108 & 5 \\
\hline
\end{tabular}


divided into two groups (a training sample and a examination sample) and classified into five categories. Table 1 illustrates the performances of the firms according to each ratio and their classification.

From Table 1, we have a sequence relation set. So, we have a linear programming problem. Solving it, we can get the optimal weights $w^{*}$ and ideal point $x^{*}$.

$$
w^{*}=\left(\begin{array}{c}
0.0699 \\
0.0100 \\
0.0100 \\
0.1154 \\
0.0100
\end{array}\right) \quad, \quad x^{*}=\left(\begin{array}{c}
0.8735 \\
-4.6423 \\
0.3161 \\
1.0913 \\
-8.9744
\end{array}\right) .
$$

Table 2 gives the square distance of firms in training sample. Then, we use an examination sample (as Table3) for model validation. Easily, we can obtain the results as table4 shows. Combining Table4 with Table 3 and Table2, we can find that the model developed provided high classification accuracy. Only credit categories of F28, F33, F35, F36, F37 and F39 are different from examination sample information.

\section{Conclusions}

This paper focused on the identification of commercial bank customer's credit. The approach employed for developing credit assessment model is based on LINMAP approach. The method employs mathematical programming techniques to develop credit rating model. In this paper the objective was to find out a method of credit discrimination. Such a discrimination method supports credit analysts in identifying potential defaulters, thus facilitating credit-granting decisions. Of course, the applications of the LINMAP method are not only limited to credit assessment; it also involves other financial risk management fields.

\section{References}

[1] M. Doupos, K. Kosmidou, G. Baourakis, and C. Zopounidis, Credit risk assessment using a multicriteria hierarchial discrimination approach: A comparative analysis, European Journal of Operational Research, 2002(138): 392-412.

[2] West R C. A Factor-analysis Approach to Bank Condition. Journal of Banking Finance, 1985, 9:253 266.

[3] Alastair G., Corporate credit analysis, Glenlake Publishing Company Limited, 2000.

[4] Hwang ,C. L. and Yoon, K. S., Multiple attribute decision making, Springer-Verlag , Berlin, 1981 .

[5] Zhou Z.F., Tang X.W., Mu T.Y. and Lu Y.J. An multi-targets evaluation approaches to customers credit, Proceedings of 2003 International Conference on Management Science \& Engineering, USA, Aug. 2003.

[6] Altman. E. I. and Saunders. A., Credit risk measurement: developments over the last 20 years, Journal of Banking and Finance, 1998(21): 1721-1742. 
[7] Altman. E. I., Financial ratios, discriminant analysis and the prediction of corporate bankruptcy. Journal of Finance, 1968, 23: 589 609.

[8] Press S J, Wilson S. Choosing between logistic regression and discriminant analysis, J. Amer. Statist. Asoc. , 1978, 73:699 705.

[9] Srinivasan, V. and Shocker, A. D. Linear programming techniques for multimensional analysis of preference, Psychometica, 1973:337.

[10] Chen LH, Chiou TW: A fuzzy credit -rating approach for commercial loans: a Taiwan case, OMEGA., The International Journal of Management Science, 1999(27) P.407-19.

[11] Myer P A, Pifer H. Prediction of bank failures, Journal of Finance, 1970, 25: 853 868.

[12] Barth J R, Brumbaugh R D, Sauerhaft D. Thrift institution failures: estimating the regulator's closure rule, G.G. Kaufman(Ed), Research in Financial Services, Greenwich, CT: JAI Press, 1989, 1.

[13] Caouettee J.B., Altman E.I. and Narayanan P., Managing credit risk: the next great financial challenge, John Wiley \& Sons, 1998.

[14] Zhou Z.F., Tang X.W. and Shi Y., The mathematical structure on credit rating, Fur East Journal of Applied Mathematics, 2005(19).

[15] Zhou Z.F., Tang X.W., The ordering relation and dominance structure of indexes space for credit, Systems Engineering-Theory \& Practice, 2004 (24): 9-15 (in Chinese).

[16] Zhou Z.F., Tang X.W. and Mou T.Y., The optimization techniques approach to customer's credit, Proceedings of ICSSSE'2003, Hongkong, 2003.10: 177-182.

[17] Zhou Z.F., Tang X.W. and Shi Y., Estimate errors on credit evaluation of commerce banks, Lecture Notes in Computer Science, 2005 (3227): 229-233. 